\title{
In vitro analysis of the Antennapedia P2 promoter: identification of a new Drosophila transcription factor
}

\author{
Karen K. Perkins, Gina M. Dailey, and Robert Tjian \\ Howard Hughes Medical Institute, Department of Biochemistry, University of California, Berkeley, California 94720 USA
}

\begin{abstract}
We have investigated the transcriptional regulation of the Antennapedia P2 (Antp P2) promoter using nuclear extracts prepared from Drosophila embryos. Transcriptional analysis of deletion mutants reveals the presence of multiple cis-regulatory elements located both upstream and downstream of the start site. One of the elements appears to mediate negative regulation, since deletion of this element results in higher levels of transcription. Several factors that interact with these control elements have been detected and isolated. One DNA-binding protein, Drosophila Transcription Factor-1 (DTF-1), specifically recognizes the consensus sequence GCAACA $/ c^{G} / c$ that is reiterated four times within an upstream activating element. DTF-1 was purified by sequence-specific DNA affinity chromatography and identified as a doublet of $\sim 50 \mathrm{kD}$. Purified DTF-1 enhances transcription from the Antp P2 promoter 7- to 15-fold in a binding site-dependent manner.
\end{abstract}

[Key Words: Drosophila; Antennapedia ; transcription]

Received August 25, 1988; revised version accepted October 4, 1988.

Drosophila embryogenesis and the determination of cellular fates involves the temporally programmed and spatially restricted expression of genes that are governed by a hierarchical network of maternal, segmentation, and homeotic regulatory factors (for review, see Mahowald and Hardy 1985; Scott and O'Farrell 1986; Akam 1987; Scott and Carroll 1987). The homeotic gene Antennapedia (Antp) plays a central role in this developmental pathway and is required to establish the identities of the first and second thoracic segments of the fly. In fact, the absence of the Antp gene results in lethality during the early larval stages, with the embryos bearing a transformation of thoracic segments into more anterior structures (Wakimoto and Kaufman 1981). Understanding the mechanisms that mediate the regulated expression of Antp would provide further insight concerning the molecular events that determine cellular fates during Drosophila embryogenesis.

The molecular cloning and characterization of the Antp gene revealed an unusual structure comprising 100 $\mathrm{kb}$ of DNA and eight exons. Transcription initiates early during embryogenesis from two distinct promoters (designated $\mathrm{Pl}$ and $\mathrm{P} 2$ ) that are located $70 \mathrm{~kb}$ apart (Laughon et al. 1986; Schneuwly et al. 1986; Stroeher et al. 1986). Several studies have suggested that the expression of the Antp gene is regulated at the level of transcription. For example, there is a direct correlation between the cellular localization of Antp transcripts and protein in the embryo (Carroll et al. 1986; Wirz et al. 1986). Furthermore, the regions of the embryo altered by Antp mutations are identical to those in which Antp RNA is dis- tributed (Levine et al. 1983; Harding et al. 1985; Martinez-Arias 1986). Recent studies indicate that transcripts resulting from $\mathrm{P} 1$ and $\mathrm{P} 2$ are localized in spatially distinct regions of the embryo (A. Martinez-Arias et al., pers. comm.), and that the two promoters are regulated independently by different cis-acting elements (Jorgensen and Garber 1987).

As an approach to understanding Antp transcription, we have analyzed the expression of the Antp P2 promoter in vitro. Genetic studies have identified many loci that regulate Antp gene expression (Hafen et al. 1984; Ingham and Martinez-Arias 1986). Undertaking a biochemical analysis of Antp transcription has the potential to reveal mechanisms by which genetically identified regulators of Antp mediate gene expression and at the same time lead to the identification of regulatory factors that have not been detected previously. In several cases, the isolation and biochemical characterization of new transcription factors from Drosophila has resulted in a greater understanding of the molecular events that mediate developmental regulation (Heberlein et al. 1985; Biggin and Tiian 1988).

It has been demonstrated that sequences within $2 \mathrm{~kb}$ upstream and $200 \mathrm{bp}$ downstream of the Antp P2 start site contain elements required for spatially restricted expression of Antp P2 RNA in the Drosophila embryo (A. Boulet and M.P. Scott, pers. comm.). By studying Antp $\mathrm{P} 2$ transcription in extracts prepared from Drosophila embryos, we have detected transcriptionally important cis-acting DNA elements within 200 bp upstream and downstream of the Antp P2 start site. Several 
sequence-specific DNA-binding proteins have been isolated that interact with these elements. One of these factors, Drosophila Transcription Factor-1 (DTF-1), has been purified to homogeneity. We show here that purified DTF-1 is capable of activating transcription from the Antp P2 promoter in a binding site-dependent manner.

\section{Results}

Transcription from the Antp P2 promoter in Drosophila embryo extracts

Previous studies demonstrated that a number of Drosophila, human, and viral promoters are transcriptionally active in nuclear extracts prepared from Drosophila embryos (Heiermann and Pongs 1985; Soeller et al. 1988). Furthermore, in vitro transcription from Drosophila promoters in extracts from embryos at different developmental stages mimics their temporal profile of expression in vivo (Biggin and Tiian 1988; Heberlein and Tiian 1988). Therefore, we used these extracts (prepared from embryos between 0 and $12 \mathrm{hr}$ of development) to study the transcriptional control of the Antp $\mathrm{P} 2$ promoter in vitro. Our results indicate that the Antp P2 promoter is transcribed efficiently in these extracts (Fig. 1, lanes

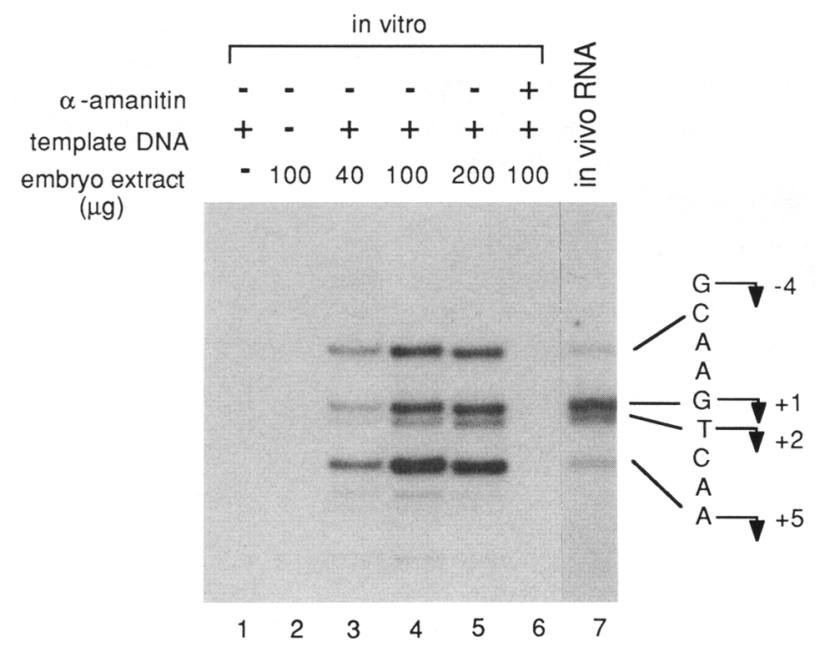

Figure 1. Transcription from the Antp $\mathrm{P} 2$ promoter in vitro. In vitro transcription reactions $(25 \mu \mathrm{l})$ contained P2 5' $\Delta-600$ DNA $(0.5 \mu \mathrm{g}$; described under Experimental procedures) and varying levels of the Drosophila embryo nuclear extract $124 \mathrm{mg}$ of pro$\mathrm{tein} / \mathrm{ml}$ ) where indicated. $\alpha$-Amanitin was added to a final concentration of $1 \mu \mathrm{g} / \mathrm{ml}$ (lane 6). The Antp P2 start sites in vivo (lane 7) were detected by primer extension of total cellular RNA $(60 \mu \mathrm{g})$ isolated from Drosophila embryos as described (Heberlein and Tjian 1988). Primer 1 was utilized for primer extension analysis of in vitro- and in vivo-synthesized RNA and also for DNA sequencing. Primer 1 is a 23-nucleotide oligomer $15^{\prime}$ CGCGT GAAAC GACGG CAAAA CCG-3') that is complementary to the sequence between +87 and +65 bp with respect to the Antp P2 start site. In vitro transcription and primer extension analysis were carried out as described (Heberlein et al. 1985). Reaction products were subjected to $8 \%$ polyacrylamide sequencing gel electrophoresis and visualized by autoradiography.
3-5). Initiation was found to occur from four start sites and was template and extract dependent. It was abolished in the presence of $\alpha$-amanitin $(1 \mu \mathrm{g} / \mathrm{ml})$, indicating that transcription is mediated by RNA polymerase II (Fig. 1, lanes 1, 2, and 6). Although Antp P2 transcription initiates from the same four start sites in vivo and in vitro (Fig. 1, lane 7), the efficiency with which these sites are utilized is somewhat different. In vivo there is one predominant start site, which we have defined as +1 and which corresponds to nucleotide 621 in exon C (Laughon et al. 1986). In vitro, three of the four sites $(-4,+1,+5)$ are utilized with approximately equal efficiency. We estimate that the level of transcription in vitro from these four start sites combined is $\sim 0.3$ transcripts per template per hour, which is consistent with the transcription rates of other Drosophila promoters in these extracts (Biggin and Tiian 1988).

\section{Analysis of Antp P2 cis-acting control elements}

Since we had determined that the Antp P2 promoter was active in embryo extracts, we could begin to identify the sequences surrounding the P2 start site that were required for transcriptional activity. Therefore, we constructed a series of deletion mutants lacking sequences upstream or downstream of the Antp P2 start site (Figs. $2 \mathrm{~B}, 3 \mathrm{~B})$. Analysis of $5^{\prime}$ deletion mutants revealed the presence of at least two important transcriptional control regions (elements A and B; Fig. 2A, B). The progressive deletion of sequences between -170 and $-62 \mathrm{bp}$ resulted in a stepwise reduction in the level of transcription (Fig. 2A, lanes 3-9; Fig. 2B), suggesting that this region is composed of multiple positive control elements that contribute collectively to a high level of transcription. We have designated this region element $\mathrm{A}$ and conclude that it is involved in activation of transcription from the Antp P2 start site.

In contrast, deletion of sequences within the region between -36 and -21 bp resulted in an increase in transcription (approximately fourfold) from three out of four of the Antp P2 start sites (Fig. 2A, lanes 13-15), suggesting the presence of a negative control element, which we have designated as element $B$. To ascertain that the increase in transcription as a result of deleting element B was not due to cryptic positive-acting elements within the vector DNA that were brought into close proximity to the P2 start site, we constructed templates containing insertions of random DNA fragments ( $\lambda$ Sau3A DNA fragments) between the vector and Antp DNA. Transcription from these insertion/deletion mutants in vitro was at a level that is consistent with the hypothesis that there is a negative regulatory element between -36 and -21 bp of the Antp P2 promoter /data not shown).

To determine whether there were elements downstream of the Antp P2 start site /within the untranslated leader) that were important for transcription, we measured the activity of a series of $3^{\prime}$ deletion mutants (Fig. $3 A, B \mid$. Our results reveal the presence of at least one positive control element (element $C$ ) that lies downstream 

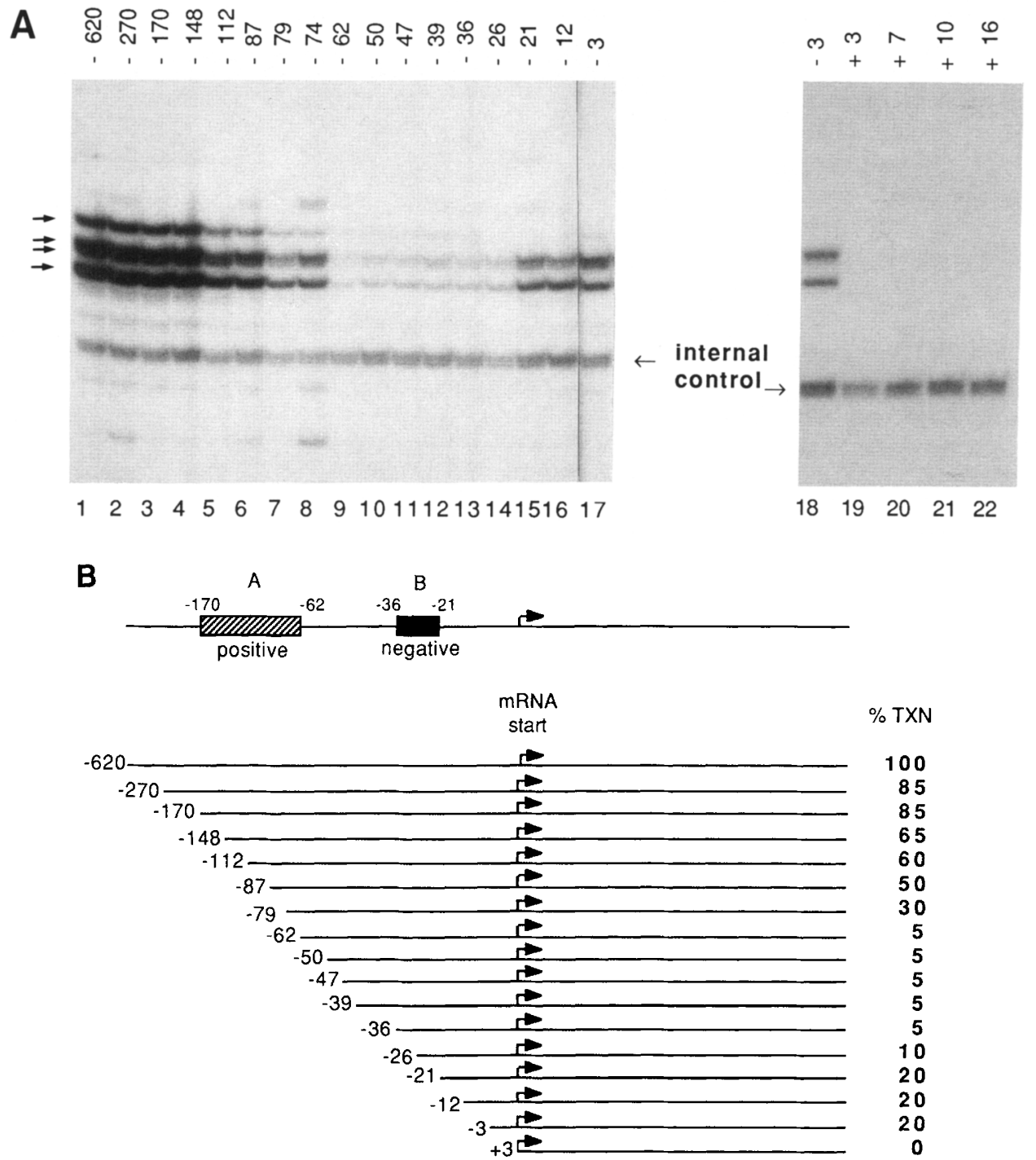

Figure 2. Transcriptional analysis of a series of $5^{\prime}$-deletion mutants of the Antp P2 promoter. $(A)$ Transcription reactions $(25 \mu l)$ contained supercoiled Antp P2 promoter deletion mutant templates $0.1 \mu \mathrm{g}$ of DNA; described in Experimental procedures) as indicated above each lane. Reactions also contained pHpHL supercoiled DNA ( $30 \mathrm{ng}$ ) as an internal control and Drosophila embryo nuclear extract (120 $\mathrm{g}$ of protein). $\mathrm{pHpHL}$ is a plasmid containing the Drosophila alcohol dehydrogenase (Adh) proximal promoter that has been deleted internally between $-386 \mathrm{bp}$ and -56 bp upstream of the start site, leaving the TATA box intact (Heberlein et al. 1985). This plasmid is transcribed at a basal level and does not respond to the addition of promoter selective factors. In vitro transcription, primer extension and analysis by polyacrylamide gel electrophoresis were carried out as described in the legend to Fig. 1 . $(B)$ Schematic representation of the Antp P2 5' deletion mutant series. The numbers on the right indicate the level of transcription observed las measured by densitometric scanning of autoradiograms) with respect to Antp P2 5 ' $\Delta-620$ DNA (100\%), and were normalized to the internal control. All experiments were repeated at least four times.

of the P2 start site (between $+39 \mathrm{bp}$ and $+26 \mathrm{bp}$ ). Deletion of element $\mathrm{C}$ abolished transcription from all four start sites. We conclude from the mutational analysis of sequences surrounding the Antp P2 start site, that there are at least three distinct elements that regulate the level of Antp P2 transcription in vitro: positive and negative elements upstream (elements $\mathrm{A}$ and $\mathrm{B}$, respectively), and a positive element downstream (element C) from the Antp P2 start site.
Detection of factors that interact with cis-regulatory elements

The next step was to identify sequence-specific DNAbinding factors that might be involved in the regulation of Antp P2 transcription. Therefore, we carried out DNase I footprinting analysis of DNA fragments spanning the promoter (see legend to Fig. 4). A protein fraction derived from S300 gel filtration chromatography was used, which contained many of the DNA binding 
Figure 3. In vitro transcription of a $3^{\prime}$ deletion mutant series. $(A)$ Transcription reactions $(25 \mu \mathrm{l})$ contained the Antp P2 promoter deletion mutants $(0.1 \mu \mathrm{g}$ of DNA; constructed as described under Experimental procedures) as indicated above each lane. Reactions also contained plasmid $\mathrm{pHpHL}$ ( $30 \mathrm{ng}$ ) as an internal control and Drosophila embryo nuclear extract $(120 \mu \mathrm{g}$ of protein). In vitro transcription, primer extension, and analysis by polyacrylamide gel electrophoresis were carried out as described (legend to Fig. 1). Primer 1 (legend to Fig. 1) was used for primer extension analysis of transcription reactions in lanes 1-3. Primer 2 was used for primer extension analysis of transcription reactions in lanes 4-12. The efficiency of transcription from the Antp P2 5' $\Delta+92$ mutant as measured by either of these primers is equivalent. Primer 2 is a 22-nucleotide oligomer $\left(5^{\prime}\right.$-TACGA ATTCG AGCTC GGTAC CC-3') that is complementary to the polylinker in plasmid pUCl18. The distance between the polylinker and the Antp P2 start sites decreases as Antp P2 DNA $3^{\prime}$ of the start site is deleted, resulting in the production of progressively smaller extension products. $(B)$ Schematic representation of $3^{\prime}$ deletion mutants. The numbers on the left indicate the level of transcription observed (as measured by densitometric scanning of autoradiograms) with respect to Antp P2 3' $\Delta+658$ DNA ( $100 \%$ using primer 1 or primer 2 ).
A

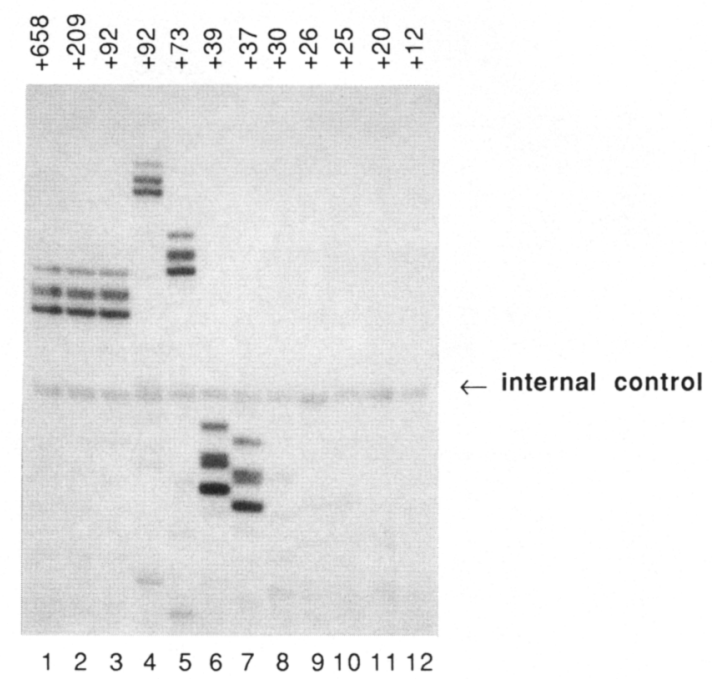

B

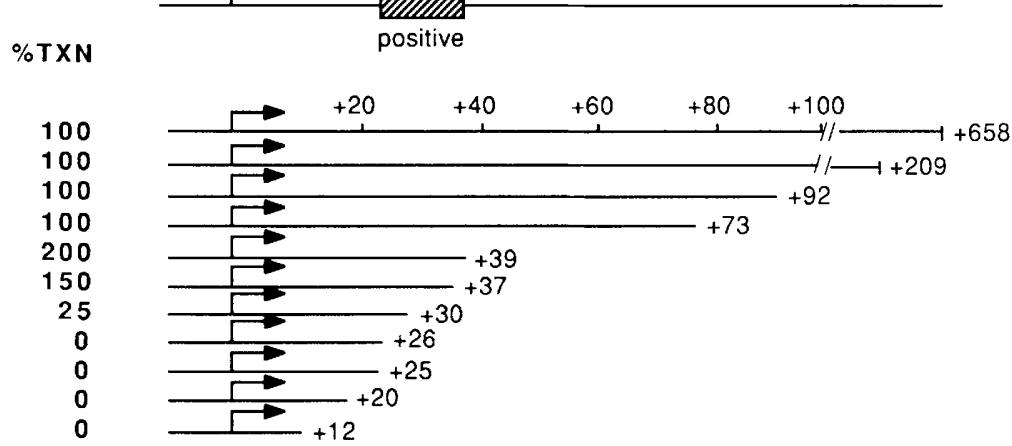

activities present in the nuclear extract /data not shown|. Footprinting with this partially purified fraction resulted in DNase I protection of several distinct regions surrounding the Antp P2 start site (designated I-V, Fig. $4 \mathrm{~A}$ ), a subset of which coincided with elements $A$ and $B$ (that we have determined to be important for transcriptional activation).

Factors binding to the region downstream of the P2 start site were detected using a nuclear extract and a DNA fragment spanning the region between $-62 \mathrm{bp}$ and +358 bp (Fig. 4B). Approximately four protected regions were observed (designated W, X, Y, and Z; Fig. 4B, lanes 6 and 7). Interestingly, one footprint (region W) overlaps with the $3^{\prime}$ element $C$, suggesting that this factor might be a transcriptional activator. These DNase I footprinting analyses indicate that several regions surrounding the Antp P2 promoter are recognized by sequence-specific DNA-binding proteins present in Drosophila embryos.

\section{Separation of factors that bind to the Antp P2 promoter}

Having detected multiple DNA binding activities that interact with sequences coincident or overlapping with transcriptional control elements of the Antp P2 promoter, it was important to separate the various DNAbinding proteins and study their biochemical properties individually. As a first step toward characterizing these putative transcription factors, three DNA-binding proteins that recognize sequences between +1 and -110 bp were isolated using sequence-specific DNA affinity chromatography (see Experimental procedures).

One factor, designated DTF-1 (Fig. 5A, lanes 2 and 3) recognized specifically four sites within protected regions II and III. A sequence GCAACA $/ \mathrm{C}^{\mathrm{G} / \mathrm{C}}$ was found that is reiterated at least four times throughout regions II and III, suggesting that this octamer sequence may represent a recognition element for DTF-1. In support of this idea, the putative recognition sequence was present on all three different affinity columns used to isolate DTF-1 (see Experimental procedures), but each synthetic octamer sequence was flanked by different adjacent sequences. Therefore, we conclude that this factor recognizes the sequence GCAACA $/ \mathrm{C}^{\mathrm{G}} / \mathrm{C}$. Interestingly, three of these consensus sequences lie within the positive transcriptional control element $A$.

Two other DNA-binding proteins were isolated that appear to recognize overlapping sequences within foot- 
A

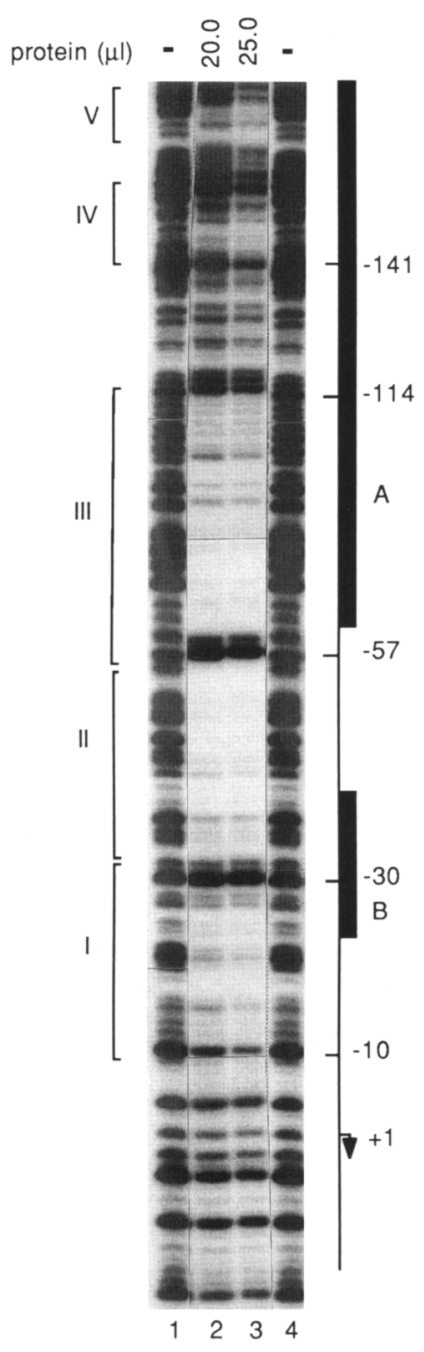

B

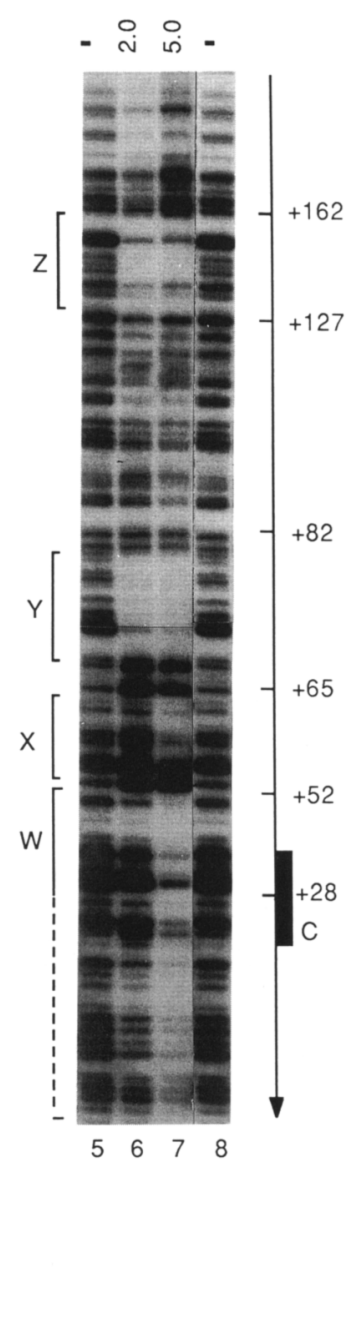

Figure 4. Detection of factors binding to the Antp P2 promoter. $(A)$ Reactions contained the indicated amounts of the S300 pooled fractions $(1.2 \mathrm{mg} / \mathrm{ml}$; lanes 2 and 3). The footprinting probe used was an MluI-NsiI restriction fragment $(3$ fmoles, spanning the distance between +85 and -391 bp with respect to the Antp P2 start site) from plasmid P2 $5^{\prime} \Delta-620$. The probe was $5^{\prime}$-end-labeled with $\left[\gamma^{-32} \mathrm{P}\right] \mathrm{ATP}$ and T4 polynucleotide kinase at the MluI site. Brackets on the left depict the regions of DNA (I-V) that are protected from DNase I cleavage, and the numbers on the right indicate the boundaries (in bp) of each of the footprints. $(B)$ Reactions contained the indicated amounts of the embryo nuclear extract (10-40\% AS, $24 \mathrm{mg}$ of protein $/ \mathrm{ml}$; lanes 6 and 7$)$. The footprinting probe used was an ASP718/NarI restriction fragment 3 fmoles, spanning the distance between -62 and +358 bp with respect to the Antp P2 start site) from plasmid Antp P2 $5^{\prime} \Delta-62$. The probe was $5^{\prime}$-end-labeled with $\left[\gamma^{-32} \mathrm{P}\right] \mathrm{ATP}$ and T4 polynucleotide kinase at the ASP718 site. Brackets on the left depict the regions of DNA $(\mathrm{W}, \mathrm{X}, \mathrm{Y}, \mathrm{Z})$ that are protected from DNase I digestion, and the numbers on the right indicate the boundaries (in bp) of each of the footprints. All DNase I footprinting reactions $(50 \mu l)$ contained nonspecific DNA [ 1 $\mu \mathrm{g}$ of poly $(\mathrm{dI} \cdot \mathrm{dC})]$ and were carried out as described (Heberlein et al. 1985). Reactions were analyzed by $6 \%$ polyacrylamide sequencing gel electrophoresis and visualized by autoradiography.

by high-performance liquid chromatography. Fractions from each stage of the purification were assayed for DTF-1-specific DNA binding activity. Active fractions were then analyzed by SDS gel electrophoresis (Fig. 6A). We estimate that from 250 grams of Drosophila embryos $\sim 40 \mu \mathrm{g}$ of DTF-1 were obtained. Purified DTF-1 contained two polypeptide species that migrated as a doublet of $\sim 50 \mathrm{kD}$ and was purified $\sim 33,000$-fold.

To demonstrate unequivocally that the $50-\mathrm{kD}$ polypeptide doublet possessed DTF-1-binding activity, we carried out renaturation of the protein eluted from an SDS-polyacrylamide gel. For this experiment, affinitypurified DTF-1 was subjected to SDS gel electrophoresis. The gel was divided into different slices (as indicated in Fig. 6B), and protein was eluted from each slice, renatured, and assayed for DTF-1 binding activity (Fig. 6C). Only protein eluted from gel slice 4 that contained the $50-\mathrm{kD}$ polypeptide doublet possessed DTF-1 binding activity (Fig. 6C, lane 12). These results confirm that purified DTF-1 resides in a protein doublet of $50 \mathrm{kD}$. 
A

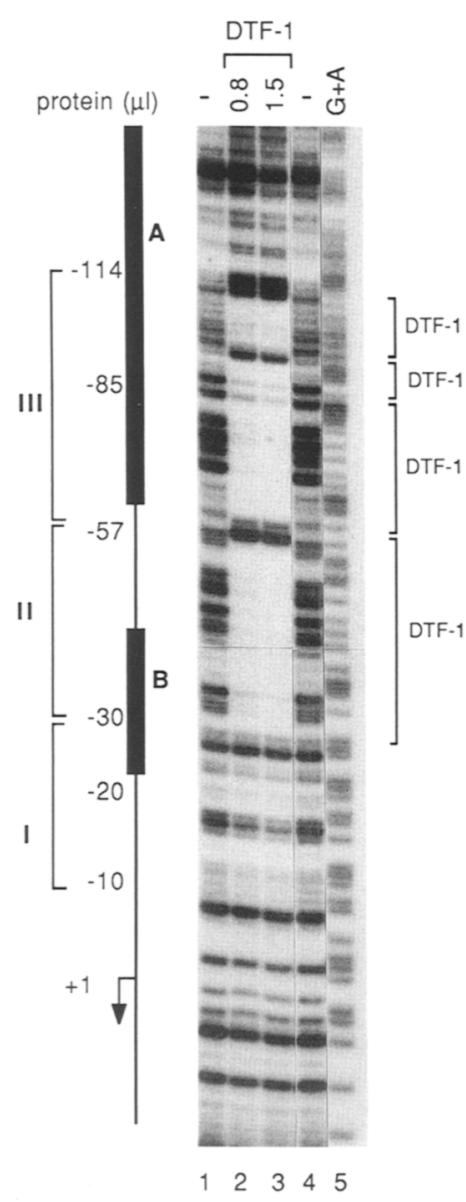

B

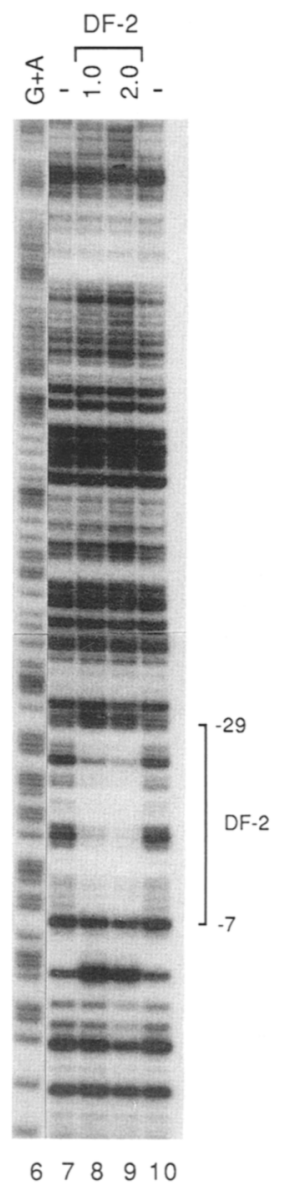

C

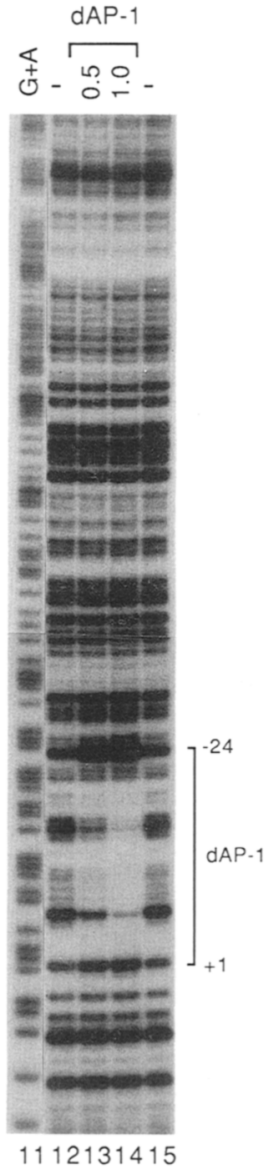

Figure 5. DNase I footprinting of isolated factors on the Antp P2 promoter. $(A-C)$ DNase I footprinting was carried out as described (Heberlein et al. 1985) using the footprinting probe $(3$ fmoles) described in Fig. 4A. Reactions contained the indicated amount of DTF-1, DF-2, or dAP-1 isolated as described in Experimental procedures. The Antp P2 promoter and the various regions footprinted by the S300 pool (I,II,III) are depicted by the drawing on the left. The brackets on the right of each footprint indicate the boundaries of the various footprints.

\section{DTF-1 activates transcription in vitro}

The in vitro transcriptional activity of DTF-1 was measured by using a Drosophila extract that had been depleted of DTF-1 using the DTF-1 sequence-specific affinity resin. In the DTF-1-depleted extract, the level of transcription from templates containing either four DTF-1 binding sites or lacking all DTF-1 sites was equally low (Fig. 7A, lanes 3 and 4). However, addition of increasing amounts of purified DTF-1 resulted in a substantial increase in the level of transcription (approximately sevenfold) that was dependent upon the presence of DTF-1 binding sites. These results indicate that DTF-1 can act directly as a sequence-specific transcription factor.

Since DTF-1 binds to four sites within the Antp P2 promoter region, it was of interest to determine the number of binding sites required for transcriptional activation by DTF-1. Therefore, we measured the level of transcription from templates that either lacked DTF-1 sites or possessed one, two, or four DTF-1 sites. As expected, extracts depleted of DTF-1 directed transcription from all four templates at equally low levels (Fig. 7B, lanes 15-18). Addition of purified DTF-1 resulted in a substantial enhancement of transcription from templates containing either two or four DTF-1 binding sites (Fig. 7B, lanes 19 and 20). In contrast, the addition of DTF-1 had no effect on templates that lacked DTF-1 sites or on templates that contained only the promoterproximal DTF-1 binding site (Fig. 7B, lanes 21 and 22). However, the inability of the template containing only one DTF-1 binding site to respond transcriptionally to added DTF-1 is not due to a lack of DTF-1 DNA binding, because DNase I footprinting confirmed that the single GCAACA ${ }^{\mathrm{T}} / \mathrm{C}^{\mathrm{G}} / \mathrm{C}$ site is fully capable of binding DTF-1 (data not shown).

\section{Discussion}

\section{In vitro transcription from the Antp P2 promoter}

A striking feature of the Antp P2 promoter is that it consists of several distinct types of regulatory elements including positive as well as negative elements that are clustered within $170 \mathrm{bp}$ upstream of the start site (Fig. 8 ), and these elements respond efficiently to specific Drosophila embryo DNA-binding factors in cell-free transcription reactions. Furthermore, Antp P2 contains at least one downstream cis-acting control element that 
A

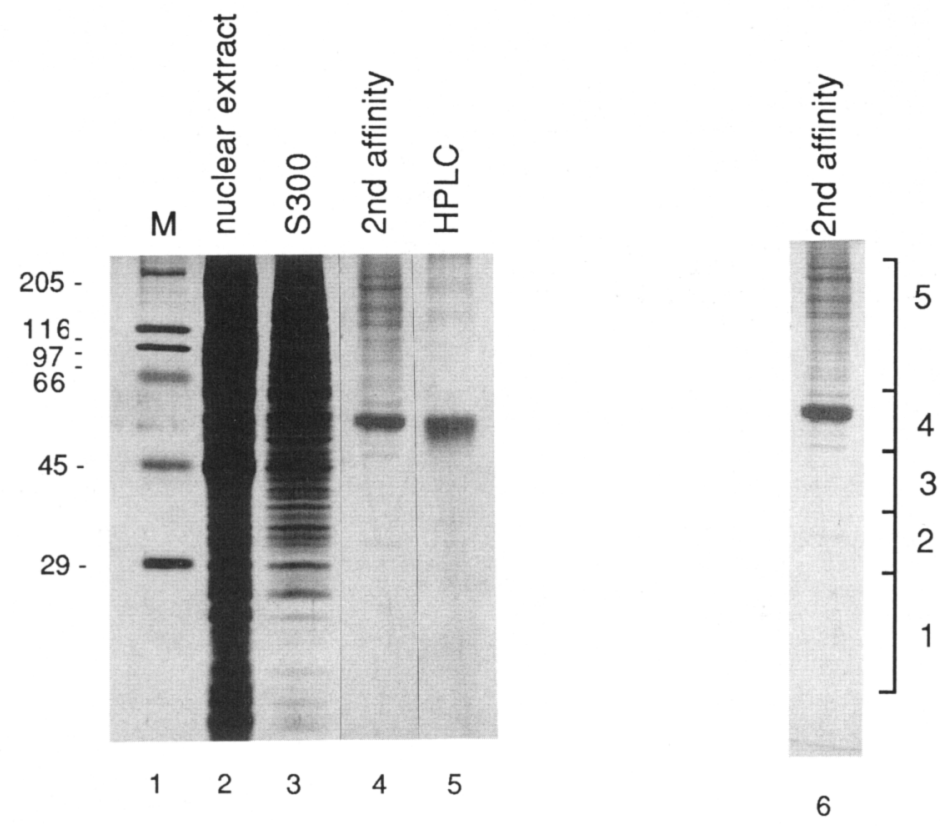

C

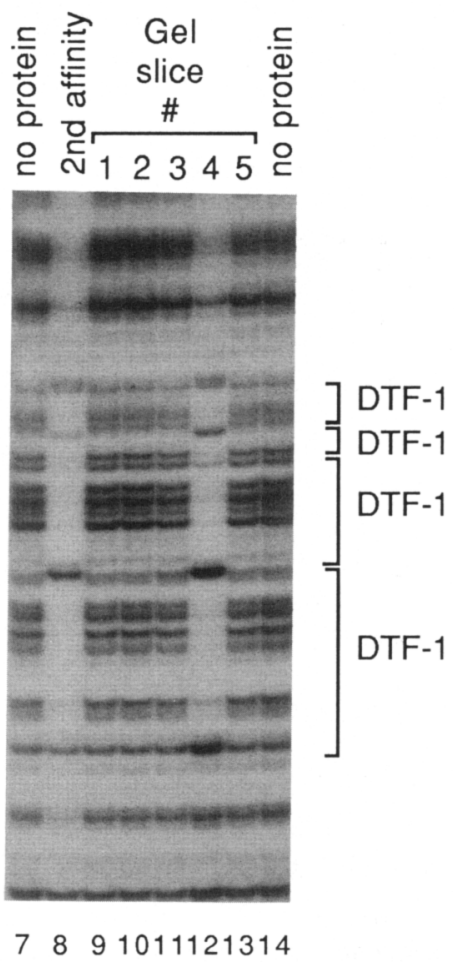

Figure 6. Purification and identification of DTF-1. (A) Protein fractions from various stages of the purification were subjected to $10 \%$ SDS-polyacrylamide gel electrophoresis and visualized by silver staining. The left lane displays molecular weight standards $(M$, sizes in $\mathrm{kD}$ ). The amount of protein in each subsequent lane is as follows: nuclear extract, $20 \mu \mathrm{g}$ of protein, 0.4 footprinting units; S300, $6 \mu \mathrm{g}$ of protein, 0.8 footprinting units; second affinity, $0.3 \mu \mathrm{g}$ of protein, 150 footprinting units; HPLC fractions, $0.3 \mu \mathrm{g}$ of protein, 150 footprinting units. $(B)$ SDS-polyacrylamide gel analysis of second-pass affinity-purified DTF- 1 . The numbers and brackets on the right indicate the boundaries of each gel slice that was used for renaturation (according to the method of Briggs et al. 1986). (C) DNase I footprinting analysis of second-pass affinity-purified DTF-1 (lane 8), and of protein eluted and renatured from the SDS-polyacrylamide gel slices (lanes 9-13, and depicted in Fig. 6B). The footprinting probe used was described in the legend to Fig. 4 . Reaction products were subjected to $8 \%$ polyacrylamide sequencing gel electrophoresis and visualized by autoradiography.

lies within $40 \mathrm{bp}$ of the start site. Thus, it is likely that there are various synergistic and antagonistic interactions that are combined to regulate Antp P2. Therefore, this promoter provides an ideal system with which to analyze the interplay of multiple transcription factors and how they contribute to complex patterns of gene expression during embryogenesis.

To begin the analysis, we have demonstrated that RNA synthesis from Antp P2 is accurate and efficient in Drosophila embryo nuclear extracts. The presence of four different initiation sites on the Antp P2 promoter is intriguing. It is possible that Antp P2 is transcribed from multiple sites because it lacks an upstream TATA homology which is thought partly to be responsible for fixing the transcription initiation site (Mathis and Chambon 1981). The Drosophila engrailed (en) and Deformed $(D f d)$ genes also lack TATA boxes (Regulski et al. 1987; Soeller et al. 1988). Transcriptional analysis of $e n$ in vitro has revealed that it also utilizes multiple transcription initiation sites. The possibility exists that these genes contain other sequences that function to position the start site. It has been suggested that the sequence TCGCCAGCG between -9 and -1 bp upstream of the $D f d$ start site might be involved in positioning the site of transcription initiation, and that this sequence is similar to the Antp P2 sequence TCACTGGCG that lies between -3 and -11 bp $\{\mathrm{Re}-$ gulski et al. 1987). However, the transcriptional analysis of $5^{\prime}$ deletion mutants reported here indicates that deletion of this sequence has no apparent effect on the Antp P2 initiation site. The possibility remains that this sequence plays a role in the in vivo expression of Antp and $D f d$, but further experiments would be required to establish this point.

The negative transcriptional control element upstream of the Antp P2 start site

Our experiments suggest that transcription of Antp P2 is partly under the control of a negative cis-acting element. Deletion or substitution within control element B re- 
A

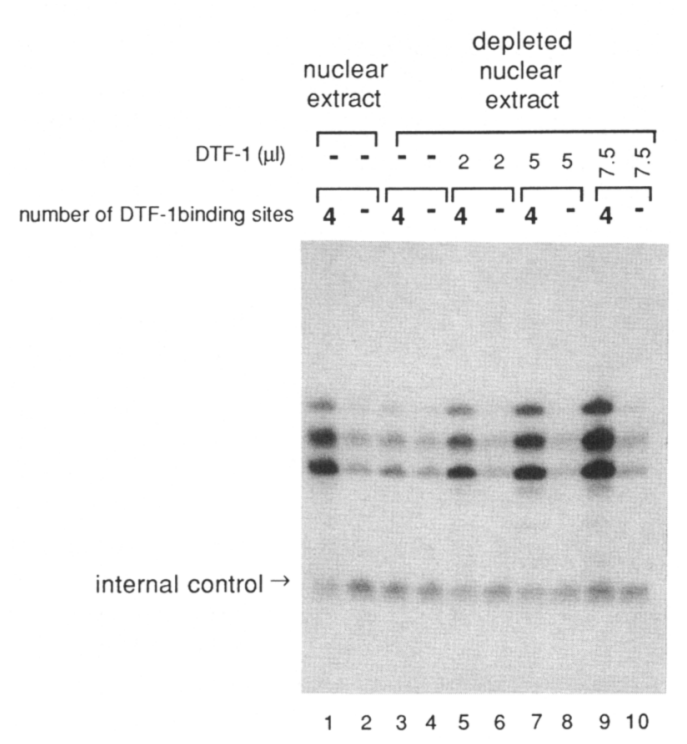

B

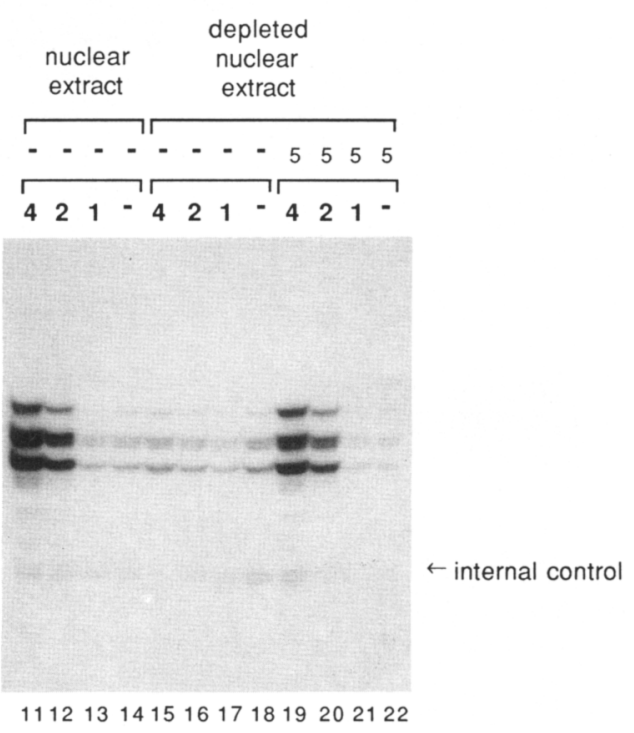

Figure 7. Primer extension analysis of DTF- 1 transcriptional activation. (A) Transcription reactions $(25 \mu l)$ contained either Antp P2 $5^{\prime} \Delta-148$ supercoiled DNA $\left(0.1 \mu \mathrm{g}\right.$, lanes $1,3,5,7$, and 9) or Antp P2 $5^{\prime} \Delta-36$ supercoiled DNA $(0.1 \mu \mathrm{g}$, lanes 2, 4, 6, 8, and 10), pHpHL $(30 \mathrm{ng})$ as an internal control, and Drosophila embryo nuclear extract (120 $\mu \mathrm{g}$ of protein, lanes 1 and 2) or extract that had been depleted of DTF-1 using a sequence-specific affinity resin (see Experimental procedures). Reactions were supplemented with the following amounts of second-pass affinity-purified DTF-1: $2 \mu \mathrm{l}$ ( 3 footprinting units/ $\mu l) ; 5 \mu l ; 7.5 \mu l$, where indicated. $(B)$ Transcription reactions

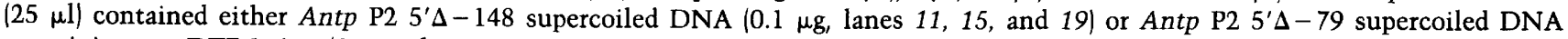
containing two DTF-1 sites $(0.1 \mu \mathrm{g}$, lanes 12,16 , and 20$)$ or Antp P2 $5^{\prime} \Delta-62$ supercoiled DNA containing one DTF-1 site $(0.1 \mu \mathrm{g}$, lanes 13,17 , and 21) or Antp P2 5's-36 supercoiled DNA lacking DTF-1 binding sites $(0.1 \mu \mathrm{g}$, lanes 14,18 , and 22). Reactions contained either Drosophila embryo nuclear extract (120 $\mu \mathrm{g}$ of protein) as indicated, or nuclear extract that had been depleted of DTF-1 using a sequence-specific affinity resin (see Experimental procedures) as indicated. Reactions in lanes 19-22 were supplemented with $5 \mu l$ (15 footprinting units) of second-pass affinity-purified DTF-1.

sulted in an increase in the level of transcription from the Antp P2 promoter. We speculate that this negative element could function on its own to repress Antp P2 during certain stages of development or in different cell types in which the positively acting factors are absent. Alternatively, the negative element could interact with the positive control elements of Antp P2 to fine-tune the expression of Antp. Several cases involving negative control of transcription in eukaryotic cells have been reported (Rio et al. 1980; Goodbourn et al. 1986; Jones 1986; Sassone-Corsi et al. 1987). Our studies have, thus far, not led to the identification of negatively acting transcription factors. Two of the factors we have isolated, Drosophila Factor-2 (DF-2) and Drosophila AP-1, recognize sequences that overlap with the negative element. However, the role of these factors in the regulation of Antp P2 expression is not yet clear. Remarkably, we have found that dAP-1 is the functional Drosophila homolog of the mammalian nuclear c-jun proto-oncogene product (K.K. Perkins, G.M. Dailey, and R. Tjian, in prep.). In addition, preliminary experiments suggest that DF-2 may be a homeo box-containing factor that also recognizes regulatory elements of the $U b x$ promoter (K.K. Perkins et al. unpubl.).
Positive transcriptional control elements of the Antp P2 promoter

We have demonstrated the presence of a positive cisacting control element upstream from the Antp P2 start site (element A). Progressive deletion of sequences within element $\mathrm{A}$ resulted in a gradual decrease in the level of transcription, suggesting that element $A$ is composed of multiple elements that contribute collectively to the overall level of transcription. For example, transcription factor DTF-1 binds tandem GCAACA $/ \mathrm{C}^{\mathrm{G}} / \mathrm{C}$ sequences within element $A$ in a manner reminiscent of $\mathrm{Spl}$ binding to multiple sites in the 21-bp repeats of the SV40 promoter (Dynan and Tiian 1983). Moreover, we have purified DTF-1 to homogeneity and demonstrated that this sequence-specific factor can activate high levels of Antp P2 transcription in a reconstituted reaction. Since embryo extracts depleted of DTF-1 transcribed P2 at a very low basal level and transcription is fully restored by purified factor, we conclude that DTF-1 must play a major role in directing the transcription of Antp P2 in vitro. The importance of DTF-1 in the regulation of Antp P2 expression during embryogenesis can best be addressed after we have isolated the gene encoding DTF-1. 
Why is the DTF-1 binding site reiterated several times within element $A$ ? One possibility is that the binding of clustered DTF-1 protomers is required to activate fully the Antp P2 promoter. Consistent with this hypothesis is the finding that the promoter-proximal DTF-1 site alone is not sufficient for transcriptional activation even though DTF-1 binds efficiently to this site. Our data suggest that at least two DTF-1 sites are required for DTF-1-mediated transcriptional activation, and that a synergistic interaction of multiple DTF-1 protein molecules may be required to trigger transcription efficiently. Further analyses of DTF-1 binding sites by generating substitution mutants may shed light on the mechanism of DTF-1 activation and its interaction with this complex array of cis-control elements.

Preliminary DNase I footprinting experiments using nuclear extracts from embryos harvested at different developmental stages suggest that DTF-1 is present early in embryogenesis (between 0 and $4 \mathrm{hr}$ ) and during the intermediate stages of embryogenesis (between 8 and 12 hr), but is not detectable late in embryogenesis (between 16 and $20 \mathrm{hr}$; K.K. Perkins and R. Tjian, data not shown). This correlates with the established temporal pattern of expression from the Antp P2 promoter in the embryo (Schneuwly et al. 1986). These findings raise the possibility that DTF-1 contributes to the temporal regulation of the Antp P2 promoter as well as to the regulation of other genes expressed during the early to middle stages of embryogenesis. However, at present we have not detected the consensus sequence GCAACA $/ \mathrm{c}^{\mathrm{G}} / \mathrm{C}$ on other characterized promoters.

It is possible that in addition to DTF-1 there are other factors not yet detected by our experiments that interact with element A to contribute to transcription from Antp P2. For example, we have found that purified GAGA transcription factor that interacts with both the $U b x$
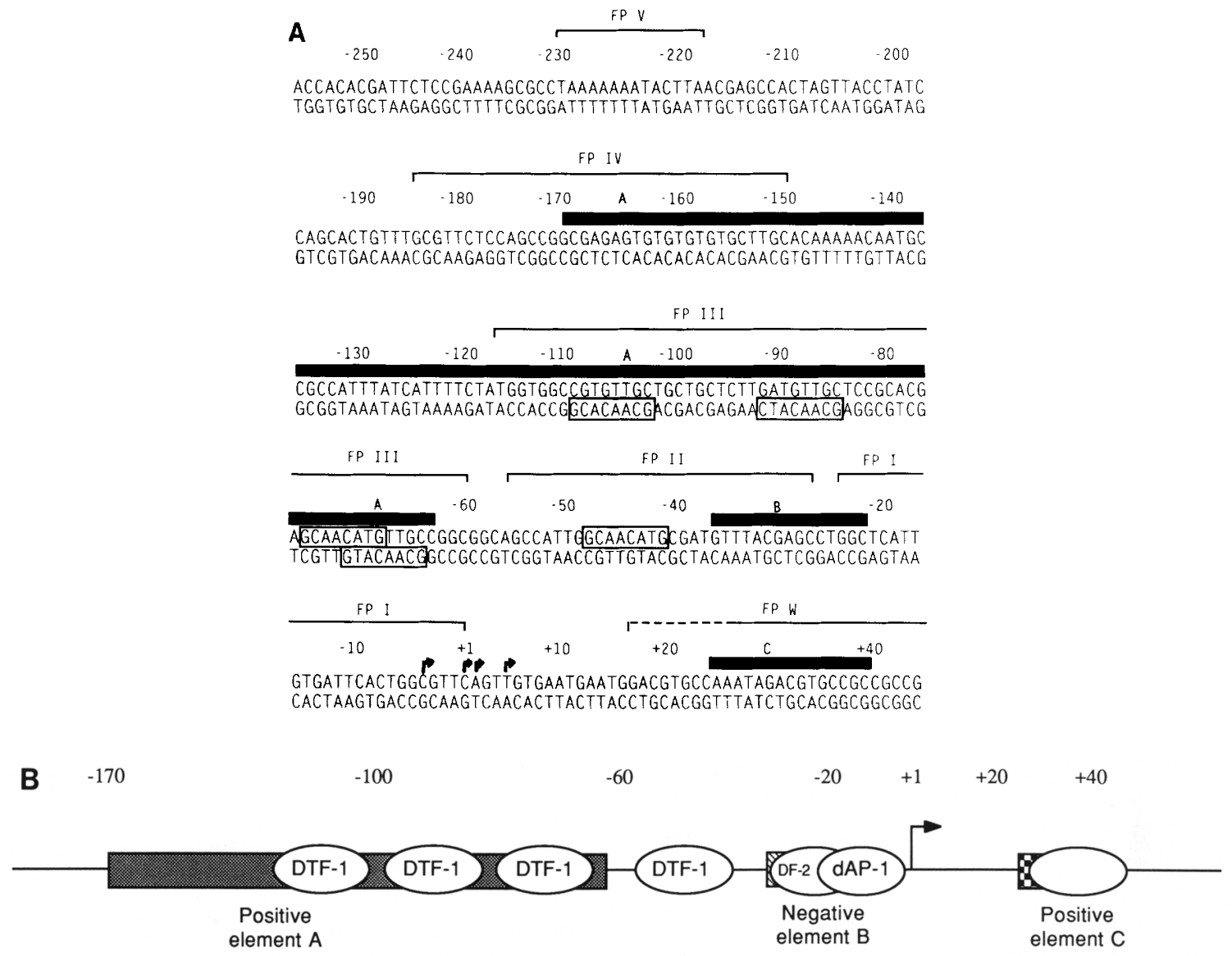

Figure 8. Summary of transcriptional control elements and factor binding sites. $(A)$ The nucleotide sequence of the Antp P2 promoter region is shown. The numbers $(-250$ to +40$)$ refer to the distance from the transcription initiation site $(+1)$. The arrows refer to the four start sites. The shaded boxes refer to the transcriptional control elements $(A, B$, and $C)$. The DTF- 1 consensus sequence GCAACA $/ C^{\mathrm{C}} / \mathrm{C}$ is displayed in boxes. The brackets refer to footprinting regions recognized by proteins in the S300 fraction and nuclear extract (FP I, II, III, IV, V, W). Regions X, Y, and Z are not within the boundaries of sequences shown. (B) A schematic diagram of the Antp P2 promoter is shown. The arrow represents the transcription start site. Protein factors (depicted as ovals) bind to specific transcriptional control elements (as represented by the shaded boxes and identified below each box). The identities of the factors are indicated in the ovals. The identities of the factors that interact with element $\mathrm{C}$ are presently unknown. 
promoter (Biggin and Tjian 1988) and the en promoter (Soeller et al. 1988) also weakly interacts with sequences within element A (K.K. Perkins and R. Tjian, unpubl. data). It is possible that the GAGA factor interacts with DTF-1 to coordinate the level of transcription from the Antp P2 promoter. Further experiments are required to elucidate the role, if any, of the GAGA factor in Antp P2 transcription.

Interestingly, we have detected a transcriptional control element with the 5'-untranslated leader of Antp P2 (element $\mathrm{C}$ ) that is active in vitro. Although cis-acting elements located downstream of the transcription initiation site are unusual in mammalian and viral genes, they appear to be more common in Drosophila promoters. For example, the en (Soeller et al. 1988), Ubx (Biggin and Tiian 1988), and 74EF ecdysone-responsive (C. Thummel, pers. comm.) promoters all contain important downstream regulatory sequences. This raises the possibility that these promoters share similar mechanisms for transcriptional activation. It has been found that both $U b x$ and en contain a consensus sequence with their downstream transcriptional control element that is recognized by homeo-domain-containing proteins (Biggin and Tiian 1988). However, the consensus sequence that is found on $U b x$ and $e n$ is not present within the $3^{\prime}$ transcriptional control element of Antp P2. This suggests that the regulation of Antp P2 by the downstream transcriptional regulatory element we have defined here is mediated by proteins distinct from those regulating en or $U b x$. In the future, we hope to purify the factors that interact with the downstream regulatory sequences of Antp P2. Together with the transcription factors we have already isolated that interact with the upstream regulatory elements, it should be possible to initiate a more complete study of the biochemical mechanisms underlying the regulation of Antp.

\section{Experimental procedures}

\section{Plasmid DNA}

The Antp P2 promoter recombinants were derived from an EcoRI subclone of $\lambda$ phage 448 (448 R4.6; Laughon et al. 1986). Antp P2 5' $\Delta-620$ contains sequences from the HindIII site at $-620 \mathrm{bp}$ to the EcoRI site at $+658 \mathrm{bp}$ (with respect to the Antp P2 start site) inserted into a pUC118 vector previously digested with HindIII and EcoRI. The Antp P2 5' and 3' deletion mutations were generated by Bal31 nuclease digestion of templates previously cut with $N$ siI $(-391 \mathrm{bp})$ or NarI $(+358 \mathrm{bp})$. KpnI linkers were ligated to the deletion end points. Antp P2 5 ' deletion mutants contain sequences from the EcoRI site (+658 bp) to the KpnI site at the deletion end point inserted into an EcoRI-KpnI-digested pUC118 vector. Antp P2 3' deletion mutants contain sequences from the HindIII site $(-620 \mathrm{bp})$ to the $K p n I$ site at the deletion end point inserted into a HindIII-KpnI digested pUC118 vector. All procedures were carried out according to Maniatis et al. (1982).

\section{Drosophila embryo nuclear extracts}

Canton-S wild-type flies were maintained in population cages at $25^{\circ} \mathrm{C}$. Embryos were collected on yeasted molasses-agar trays for $12 \mathrm{hr}$ and stored for up to 3 days at $4^{\circ} \mathrm{C}$, as described (Biggin and Tjian 1988). Nuclear extracts were typically prepared from 125 grams of embryos essentially as described (Soeller et al. 1988), except that nuclei were not pelleted by centrifugation in sucrose. The final ammonium sulfate pellet was resuspended in a volume corresponding to one-fourth the weight of the starting material $(31 \mathrm{ml})$ in a buffer containing 25 mM HEPES- $\mathrm{KOH}$ (pH 7.6), $40 \mathrm{~mm} \mathrm{KCl}, 12.5 \mathrm{~mm} \mathrm{MgCl} 2,0.1 \mathrm{~mm}$ EDTA, $1 \mathrm{mM}$ DTT, and 10\% glycerol (0.04 M/HEMG). The resulting suspension was dialyzed and centrifuged as described (K.K. Perkins and R. Tjian, submitted). The resulting nuclear extract $(\sim 24 \mathrm{mg}$ of protein $/ \mathrm{ml})$ was stored at $-70^{\circ} \mathrm{C}$. Nuclear extracts utilized in reconstituted reactions were depleted as follows. An aliquot of extract $(500 \mu \mathrm{l})$ was mixed in a $1-\mathrm{ml}$ plastic tube with DTF-1 sequence-specific affinity resin $(250 \mu \mathrm{l}$; described below), and centrifuged (K.K. Perkins and R. Tjian, submitted). The depleted extract was stored at $-70^{\circ} \mathrm{C}$.

\section{Separation of Antp P2 DNA-binding proteins}

All steps were carried out at $4^{\circ} \mathrm{C}$. To separate Antp P2 promoter DNA-binding proteins, the nuclear extract was prepared from 0 - to 12-hr embryos (125 grams of embryos) as described above, except that the supernatant from the ammonium sulfate nuclear lysis was brought to $40 \%$ saturation by the addition of $0.17 \mathrm{~g} / \mathrm{ml}$ of solid ammonium sulfate (K.K. Perkins and R. Tiian, submitted). The resulting fraction $(10-40 \%$ AS, $24 \mathrm{mg}$ of protein $/ \mathrm{ml}$ ) was stored at $-70^{\circ} \mathrm{C}$ and retained $100 \%$ of the $A n t p$ P2 promoter DNA-binding activities for at least 1 year.

Two $10-40 \%$ AS fractions were pooled $132 \mathrm{ml}, 24 \mathrm{mg}$ of protein $/ \mathrm{ml}$ ) and fractionated by heparin-agarose chromatography (heparin fraction $33 \mathrm{ml}, 11 \mathrm{mg}$ of protein $/ \mathrm{ml}$ ) followed by Sephacryl S300 gel filtration chromatography (K.K. Perkins and R. Tiian, submitted). The fractions from the $\$ 300$ column containing Antp promoter DNA-binding activity were pooled (S300 fraction $310 \mathrm{ml}, 1.2 \mathrm{mg}$ of protein $/ \mathrm{ml}$ ), supplemented with Nonidet P-40 (NP-40, 0.1\%) and poly $(\mathrm{dI}: \mathrm{dC})(3.9 \mathrm{mg})$, stirred for $10 \mathrm{~min}$ at $4^{\circ} \mathrm{C}$, and then centrifuged at $10,000 \mathrm{rpm}$ for $10 \mathrm{~min}$ in a Sorvall SS34 rotor.

The Antp P2 promoter DNA-binding proteins were then separated using $1-\mathrm{ml}$ sequence-specific DNA affinity columns (Kadonaga and Tjian 1986) previously equilibrated with 0.1 M/HEG [25 mM HEPES-KOH (pH 7.6), 0.1 mM EDTA, $1 \mathrm{~mm}$ DTT, $10 \%$ glycerol, $0.1 \mathrm{M} \mathrm{KCl}$ ] containing $0.1 \% \mathrm{NP}-40$. All first affinity column buffers contained $0.1 \%$ NP- 40 . The $\$ 300$ fraction was applied sequentially to four different affinity columns $(1-4)$ so that the flowthrough from one column was immediately applied to the next column. Affinity columns 1-4 each consisted of DNA sequences of a distinct region upstream of the Antp P2 start site. Each column was eluted with three column volumes of $1 \mathrm{M} \mathrm{KCl} / \mathrm{HEG}$ and assayed for Antp P2 promoter DNA-binding. The complementary oligodeoxynucleotides used for the columns were as follows. Column 1 consisted of sequences between $-83 \mathrm{bp}$ and $-58 \mathrm{bp}$ within footprinting region III /containing the complementary oligonucleotides 5'GATCC CGCAG CAGCA ACATG TTGCC GGCGG-3', and 5'-GATCC CGCCG GAACA TGTTG CTGCT GCGG-3'). Column 2 consisted of sequences between $-116 \mathrm{bp}$ and $-85 \mathrm{bp}$ within footprinting region III /containing the complementary oligonucleotides $5^{\prime}$-GATCG GTGGC CGTGT TGCTG CTG CT CTTGA TGTTG C-3' and 5'-GATCG CAACA TCAAG AGCAG CAGCA ACACG GCCAC C-3'). Column 3 consisted of sequences between -55 bp and -27 bp within region II (containing the complementary oligonucleotides 5'-GATCG CCATT GGCAA CATGC GATGT TTACG AGC-3' and 5'GATCG CTCGT AAACA TCGCA TGTTG CCAAT GGC-3'). 
Column 4 consisted of sequences between -24 bp and +5 bp within footprinting region I /containing the complementary oligonucleodides 5'-GATCG GCTCA TTGTG ATTCA CTGGC GTTCA GTT-3' and 5'-GATCA ACTGA ACGCC AGTGA ATCAC AATGA GCC-3'). The activity that eluted from column 1 (DTF-1) which recognized sequences between $-83 \mathrm{bp}$ and $-58 \mathrm{bp}$ (within footprinting region III) also recognized sequences between $-116 \mathrm{bp}$ and $-83 \mathrm{bp}$ and between $-55 \mathrm{bp}$ and $-27 \mathrm{bp}$ according to DNase I footprinting experiments, although no DNA-binding activity eluted from columns 2 and 3.

To separate the two overlapping DNA-binding activities that eluted from column 4 and that recognized Antp promoter sequences between +5 and $-29 \mathrm{bp}$, the $S 300$ fraction $(310 \mathrm{ml}, 1.2$ $\mathrm{mg}$ of protein $/ \mathrm{ml}$ ) was instead applied directly to three DNA affinity columns (containing the sequences of column 4) that had previously been equilibrated with $0.1 \mathrm{M} / \mathrm{HEG}$. The column was washed with 10 volumes of $0.1 \mathrm{M} / \mathrm{HEG}$ and then step eluted with HEG containing $0.2 \mathrm{M}, 0.5 \mathrm{M}$, and $1.0 \mathrm{M} \mathrm{KCl} / 3 \mathrm{ml}$ each step). The dAP-1 footprinting activity was detected in the $0.5 \mathrm{M}$ eluate; activity was pooled (first affinity, $8 \mathrm{ml}, 80 \mu \mathrm{g}$ of protein $/ \mathrm{ml}$ ) diluted to $0.1 \mathrm{M} \mathrm{KCl} / \mathrm{HEG}$ and mixed with poly $(\mathrm{dI}: \mathrm{dC})(16 \mu \mathrm{g})$ as described above, and applied to a second DNA affinity column (column $5 ; 1 \mathrm{ml}$ ) previously equilibrated with $0.1 \mathrm{~m} / \mathrm{HEG}$ containing $0.1 \%$ LDAO. $10.1 \%$ LDAO was used instead of NP-40 in all second-pass affinity column buffers). The complementary oligodeoxynucleotides used to prepare the resin (column 5) were 5'-GATCG TGACT CAGCG CG-3' and 5'-GATCC GCGCT GAGTC AC-3'. The column was washed with 10 volumes of $0.1 \mathrm{M} / \mathrm{HEG}$, step-eluted with HEG containing $0.2 \mathrm{M}$ and $0.5 \mathrm{M} \mathrm{KCl}(3 \mathrm{ml}$ each step), and then eluted with a step gradient containing $1 \mathrm{ml}$ each of $0.6 \mathrm{M}, 0.7 \mathrm{M}$, $0.8 \mathrm{M}, 0.9 \mathrm{M}$, and $1 \mathrm{M} \mathrm{KCl}$ in HEG. dAP-1 activity was obtained in the $0.7 \mathrm{M}$ and $0.8 \mathrm{M} \mathrm{KCl}$ eluates (second affinity dAP-1, $2 \mathrm{ml}$, $10 \mu \mathrm{g}$ of protein $/ \mathrm{ml}$ ), and DF-2 was obtained in the $0.2 \mathrm{M} \mathrm{KCl}$ eluate (second affinity DF-2, $2 \mathrm{ml}, 100 \mu \mathrm{g}$ of protein $/ \mathrm{ml}$ ).

\section{Purification of DTF-1}

DTF-1 was isolated as described above, with the following modifications. The $\mathrm{S} 300$ fraction was applied to an affinity column (column 6) previously equilibrated with $0.1 \mathrm{M} \mathrm{KCl} / \mathrm{HEG}$. The oligonucleotide used for column 6 was the palindromic sequence $5^{\prime}$-GATCG CAACA TGTTG C-3'. The column was eluted with three column volumes each of HEG containing 0.2 $\mathrm{M}, 0.3 \mathrm{M}, 0.4 \mathrm{M}, 0.5 \mathrm{M}$, and $1.0 \mathrm{M} \mathrm{KCl}$. The DTF-1 footprinting activity that eluted with $0.4 \mathrm{M} \mathrm{KCl}$ was pooled (first affinity 6 $\mathrm{ml}, 100 \mu \mathrm{g}$ of protein $/ \mathrm{ml}$, diluted to $0.1 \mathrm{M} \mathrm{KCl} / \mathrm{HEG}$ and subjected to a second cycle of DNA affinity chromatography using column 6 . The second affinity column was eluted with three column volumes each of $\mathrm{HEG}$ containing $0.2 \mathrm{M}, 0.3 \mathrm{M}$, and 1.0 $\mathrm{M} \mathrm{KCl}$. DTF-1 fooprinting activity was obtained in the $0.3 \mathrm{M}$ $\mathrm{KCl}$ eluate (second affinity $4 \mathrm{ml}, 10 \mu \mathrm{g}$ of protein $/ \mathrm{ml}$ ). The protein concentration in affinity-purified fractions was estimated by SDS-polyacrylamide gel electrophoresis and silver staining. The fraction was stored at $-70^{\circ} \mathrm{C}$.

Purification of DTF-1 by HPLC was carried out as described for dAP-1 (K.K. Perkins and R. Tjian, submitted) except that 100 $\mu l$ of a second affinity fraction was used as the starting material.

\section{Acknowledgments}

We are grateful to Karen Ronan for typing this manuscript and for preparation of the figures. We kindly thank John Bermingham and Matthew Scott for providing the Antennapedia
DNA. We thank Anne Boulet, John Bermingham, Alfonso Martinez-Arias, Matthew Scott, and Carl Thummel for communicating their results prior to publication. We especially appreciate the critical reading of this manuscript by Steve Bell, Naoko Tanese, Ulrike Heberlein, Steve Jackson, and Jim Kadonaga. K.K.P. is supported by a Damon Runyon-Walter Winchell Cancer Fund Fellowship, DRG-931. This work was supported in part by a research grant from the National Cancer Institute to R.T.

\section{References}

Akam, M. 1987. The molecular basis for metameric pattern in the Drosophila embryo. Development. 101: 1-22.

Biggin, M.D. and R. Tjian. 1988. Transcription factors that activate the Ultrabithorax promoter in developmentally staged extracts. Cell 53: 699-711.

Briggs, M., J.T. Kadonaga, S.P. Bell, and R. Tiian. 1986. Purification and biochemical characterization of the promoter-specific transcription factor, Spl. Science 234: 47-52.

Carroll, S.B., R.A. Laymon, M.A. McCutcheon, P.D. Riley, and M.S. Scott. 1986. The localization and regulation of Antennapedia protein expression in Drosophila embryos. Cell 47: $113-122$.

Dynan, W.S. and R. Tjian. 1983. The promoter-specific transcription factor $\mathrm{Spl}$ binds to upstream sequences in the SV40 early promoter. Cell 35: 79-87.

Goodbourn, S., H. Burstein, and T. Maniatis. 1986. The human $\beta$-interferon gene enhancer is under negative control. Cell 45: $601-610$.

Hafen, E., M. Levine, and W.J. Gehring. 1984. Regulation of Antennapedia transcript distribution by the Bithorax complex in Drosophila. Nature 307: 287-289.

Harding, K., C. Wedeen, W. McGinnis, and M. Levine. 1985. Spatially regulated expression of homeotic genes in Drosophila. Science. 229: 1236-1242.

Heberlein, U., B. England, and R. Tjian. 1985. Characterization of Drosophila transcription factors that activate the tandem promoters of the alcohol dehydrogenase gene. Cell 41: 965977.

Heberlein, U. and R. Tjian. 1988. Temporal pattern of alcohol dehydrogenase gene transcription reproduced by Drosophila stage-specific extracts. Nature 331: 410-415.

Heiermann, R. and O. Pongs. 1985. In vitro transcription with extracts of nuclei of Drosophila embryos. Nucleic Acids Res. 13: 2709-2730.

Ingham, P.W. and A. Martinez-Arias. 1986. The correct activation of Antennapedia and Bithorax complex genes requires the fushi tarazu gene. Nature. 324: 592-597.

Jorgensen, E.M. and R.L. Garber. 1987. Function and misfunction of the two promoters of the Drosophila Antennapedia gene. Genes Dev. 1: 544-555.

Jones, N.C. 1986. Negative regulation of enhancers. Nature 321: 202-203.

Kadonaga, J.T. and R. Tjian. 1986. Affinity purification of sequence-specific DNA-binding proteins. Proc. Natl. Acad. Sci. 83: 5889-5893.

Kaufman, T.C., R. Lewis, and B. Wakimoto. 1980. Cytogenetic analysis of chromosome 3 in Drosophila melanogaster: the homeotic gene complex in polytene chromosome interval 84A-B. Genetics 94: 15-133.

Laughon, A., A.M. Boulet, J.R. Bermingham, R.A. Laymon, and M.S. Scott. 1986. Structure of transcripts from the homeotic Antennapedia gene of Drosophila melanogaster: Two promoters control the major protein coding region. Mol. Cell. Biol. 6: 4676-4689. 
Levine, M., E. Hafen, R.L. Garber, and W.J. Gehring. 1983. Spatial distribution of Antennapedia transcripts during Drosophila development. EMBO I. 2: 2037-2046.

Mahowald, A.P. and P.A. Hardy. 1985. Genetics of Drosophila embryogenesis. Annu. Rev. Gen. 19: 149-177.

Maniatis, T., E.F. Fritsch, and J. Sambrook. 1982. Molecular cloning: A laboratory manual. Cold Spring Harbor Laboratory, Cold Spring Harbor, New York.

Martinez-Arias, A. 1986. The Antennapedia gene is required and expressed in parasegments 4 and 5 of the Drosophila embryo. $E M B O$ I. 5: 135-141.

Mathis, D.J. and P. Chambon. 1981. The SV40 early region TATA box is required for accurate in vitro initiation of transcription. Nature 290: 310-315.

Regulski, M., N. McGinnis, R. Chadwick, and W. McGinnis. 1987. Developmental and molecular analysis of Deformed; a homeotic gene controlling Drosophila head development. EMBO I. 6: 767-777.

Rio, D., A. Robbins, R. Myers, and R. Tjian. 1980. Regulation of simian virus 40 early transcription in vitro by a purified tumor antigen. Proc. Natl. Acad. Sci. 77: 5706-5710.

Sassone-Corsi, P., C. Fromental, and P. Chambon. 1987. A trans-acting factor represses the activity of the polyoma virus enhancer in undifferentiated embryonal carcinoma cells. Oncogene Res. 1: 113-119.

Schneuwly, S., A. Kuroiwa, P. Baumgartner, and W.J. Gehring. 1986. Structural organization and sequence of the homeotic gene Antennapedia of Drosophila melanogaster. EMBO $)$ 5: $733-739$.

Scott, M.P. and S.B. Carroll. 1987. The segmentation and homeotic gene network in early Drosophila development. Cell 51: 689-698.

Scott, M.P. and P.H. O'Farrell. 1986. Spatial programming of gene expression in early Drosophila embryogenesis. Annu. Rev. Cell. Biol. 2: 49-80.

Soeller, W.C., S.J. Poole, and T. Kornberg. 1988. In vitro transcription of the Drosophila engrailed gene. Genes Dev. 2: $68-81$.

Stroeher, V.L., E.M. Jorgensen, and R.L. Garber. 1986. Multiple transcripts from the Antennapedia gene of Drosophila melanogaster. Mol. Cell. Biol. 6: 4667-4675.

Wakimoto, B.T. and T.C. Kaufman. 1981. Analysis of larval segmentation in lethal genotypes associated with the $A n$. tennapedia gene complex in Drosophila melanogaster. Dev. Biol 81: 51-64.

Wirz, J., L.I. Fessler, and W.J. Gehring. 1986. Localization of the Antennapedia protein in Drosophila embryos and imaginal discs. EMBO I. 5: 3327-3334. 


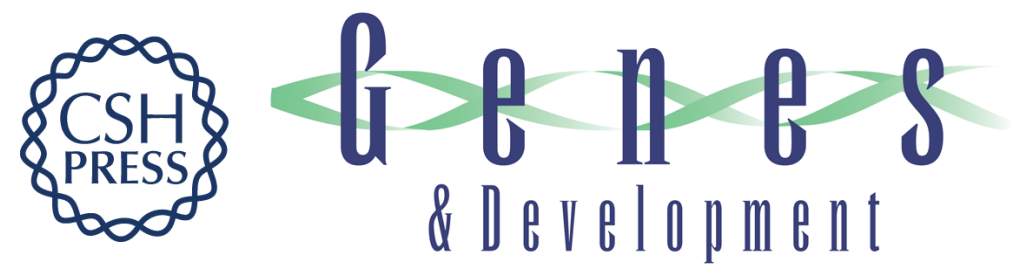

\section{In vitro analysis of the Antennapedia P2 promoter: identification of a new Drosophila transcription factor.}

K K Perkins, G M Dailey and R Tjian

Genes Dev. 1988, 2:

Access the most recent version at doi:10.1101/gad.2.12a.1615

References This article cites 31 articles, 10 of which can be accessed free at:

http://genesdev.cshlp.org/content/2/12a/1615.full.html\#ref-list-1

License

Email Alerting

Service

Receive free email alerts when new articles cite this article - sign up in the box at the top right corner of the article or click here.

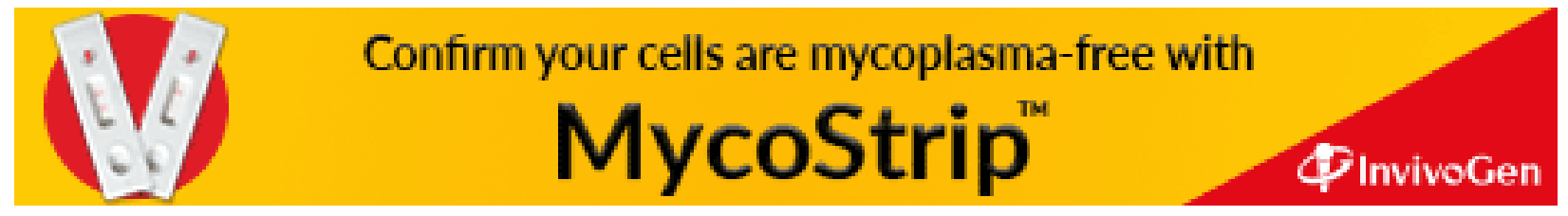

